\title{
Effectiveness of Stimulant Medications on Disruptive Behavior and Mood Problems in Young Children
}

\author{
Ian Parsley ${ }^{1}$, Zhuo Zhang ${ }^{2}$, Mark Hausmann ${ }^{3}$, Arica Lerdahl ${ }^{4}$, Brigette Vaughan ${ }^{4}$, Ryan Edwards ${ }^{4}$, Soonjo Hwang ${ }^{4}$ \\ ${ }^{1}$ Department of Psychiatry, Washington University, St. Louis, MO, USA, ${ }^{2}$ China University of Political Science and Law, School of Psychology, \\ Beijing, China, ${ }^{3}$ Daybreak Mental and Behavioral Health, Papillion, NE, USA, ${ }^{4}$ Department of Psychiatry, University of Nebraska Medical Center, \\ Omaha, NE, USA
}

\begin{abstract}
Objective: There are very few studies on the effectiveness of stimulant medications for the treatment of disruptive mood and behavior problems in young children (less than 7 years) with Disruptive Behavior Disorders (DBD). The current study aims to determine whether young children (ages 4-7) in a long-term, intensive outpatient behavioral treatment program who are receiving stimulant medications show greater improvement in mood and behavior problems compared to peers who did not.

Methods: A retrospective chart review was conducted for 97 participants diagnosed with DBD, aged 4-7 years old who were enrolled in an intensive outpatient behavioral intervention program. Pre- and post-intervention Child Behavior Checklist (CBCL) scores for disruptive behavior and mood problems were compared between the children who received stimulant medications and those who did not.

Results: Paired $t$ tests showed a statistically significant improvement in CBCL outcomes between pre- and post-intervention scores of disruptive behavior and mood problems. ANCOVA analysis, however, showed no clear further improvement in those same CBCL scores in the participants who received stimulant medications compared to the participants who did not. CBCL scores for Conduct Disorder were marginally significant for less improvement for the participants who received stimulant medications.

Conclusion: This retrospective review suggests a possibility that stimulant medications may not provide additional benefit for the long-term treatment of disruptive behavior and mood problems in young children under age 7 . Future study is warranted to evaluate the efficacy/effectiveness of stimulant medications in the treatment of disruptive behavior and mood problems in this population.
\end{abstract}

KEY WORDS: Stimulant medication; Disruptive behavior; Aggression; Young children; Effectiveness.

\section{INTRODUCTION}

The disruptive mood and behavior disorders of Conduct Disorder (CD), Oppositional Defiant Disorder (ODD), and Disruptive Mood Dysregulation Disorder (DMDD), in addition to Attention-Deficit/Hyperactivity Disorder (ADHD) are characterized by aggressive/disruptive behavior, poor emotional regulation, chronic irritability, anger outbursts, and relationship difficulties in various settings (at school,

Received: February 11, 2020 / Revised: April 14, 2020

Accepted: May 6, 2020

Address for correspondence: Soonjo Hwang

Department of Psychiatry, University of Nebraska Medical Center, 985578 Nebraska Medical Center, Omaha, NE 68198-5578, USA

E-mail: soonjo.hwang@unmc.edu

ORCID: https://orcid.org/0000-0001-5117-2468 at home, and with friends) [1,2]. Although ADHD is no longer categorized as a DBD in the Diagnostic and Statistical Manual of Mental Disorders 5th edition (DSM-5), these disorders altogether share common symptom profiles and are highly comorbid [3-8]. These disorders are highly correlated with academic difficulties, poor social skills [9], legal troubles, increased morbidity, and poorer overall functioning [10-12].

The current treatment modalities for disruptive behavior and mood symptoms related to the diagnoses of ADHD, CD, ODD, and DMDD in children and adolescents include both behavioral interventions and psychopharmacological treatments - especially psychostimulant medications [13-18]. Behavioral interventions which focus on reducing positive reinforcement for disruptive be-

(c) This is an Open-Access article distributed under the terms of the Creative Commons Attribution Non-Commercial License (http://creativecommons.org/licenses/by-nc/4.0) which permits unrestricted non-commercial use, distribution, and reproduction in any medium, provided the original work is properly cited. 
havior and increasing reinforcement for prosocial/compliant behavior, as well as those that apply predictable, contingent, and immediate responses by the caregivers are proven to be effective in reducing disruptive behavior symptoms $[16,19,20]$.

As for psychostimulant class of medications, the efficacy for the treatment of ADHD symptomatology has been well documented, particularly in the short-term $[18,21]$. In addition, there are numerous studies showing significant effect size of stimulant medications for symptoms of oppositional behavior, conduct problems, and aggression especially for children and adolescents with ADHD, with or without comorbid ODD/CD (for metaanalysis/systematic review $[22,23])$. There are also studies showing the positive effect of stimulant medication (i.e., methylphenidate) on Conduct Disorder symptoms without comorbidity of ADHD [24] and on emotional dysregulation (highly related to irritability) in youths with ADHD/CD/ODD [25].

Since most of the previous studies were conducted in randomized clinical trial settings $[22,23]$, examination of the effectiveness of the stimulant medications in a real-world setting may potentially bring an additional understanding on this topic [26]. It is noteworthy that previous studies have suggested effectiveness of stimulant medications in naturalistic settings are often smaller compared to randomized controlled clinical trial settings, for not only disruptive behaviors but even for the core symptoms of ADHD $[27,28]$. In addition, most of the studies organized the diagnostic categories as ADHD with or without comorbid CD/ODD [23]. A dimensional approach of psychopathologies across various diagnoses, especially in disruptive mood and behavior disorders, potentially can yield better understanding of the illnesses, and better predict the clinical course and prognosis $[29,30]$. Most critically, most of the previous studies focused on children aged 7 years and older, thus elementary school age and beyond. The average ages of children in most of the studies looking at the effects of stimulant medications on disruptive behavior and mood problems ranged from 7.7 to 14.4 years, with $9-10$ being the most common age range $[22,23]$. The American Academy of Pediatrics has recommended stimulant medication treatment for children with ADHD symptoms aged 6 and older, and a trial of evidence-based behavioral intervention as the first-line treatment for children with ADHD symptoms aged $4-5$ years
[31]. A very comprehensive study of the efficacy of stimulant medication (methylphenidate) for preschoolers showed significant reduction of the ADHD symptoms by methylphenidate treatment compared to placebo, although the effect size was smaller compared to the older children [32]. However, there has been virtually no comprehensive study on the efficacy or effectiveness of stimulant medications in children under age 7 with disruptive mood and behavior problems, although increasing numbers of these children are prescribed stimulant medications for these reasons [33-35].

In this study, we aimed to clarify this critically important clinical question: are stimulant medications effective for disruptive behavior and mood problems for young children (ages 4 to 7 years old) in an intensive outpatient treatment. Specifically, we investigated the dimensional changes of behavior and mood problems across various psychiatric diagnoses, and across treatment groups (behavioral intervention program alone and behavioral intervention program plus stimulant medication). Based on previous literature $[15,22,23]$, we hypothesized: (1) Both combined treatment (stimulant medication in addition to an intensive behavioral intervention program) and the behavior modification program alone would provide significant improvement in disruptive behavior and mood problems (the effectiveness in this naturalistic setting); and (2) the combined treatment would show superior effectiveness compared to the behavior modification program alone.

\section{METHODS}

\section{Participants}

All study participants were children between the ages of 4 and 7 (average age 6.1 years old) who attended a daily outpatient behavioral intervention program for young children with severe and/or chronic behavior problems. We conducted a retrospective chart review of the participants who were in the treatment program between 2012 and 2016. Clinical assessment/characterization was done through psychiatric interview by a licensed and boardcertified child and adolescent psychiatrist with the participants and their parents as a part of the initial assessment process for the program. All participants had met full DSM-5 criteria for either ADHD, ODD, or CD; see Table 1. Although there was no apparent exclusion criteria for 
Table 1. Characteristics of participants with or without stimulant medication

\begin{tabular}{|c|c|c|c|c|}
\hline Variables & Total patients $(n=97)$ & On stimulants $(n=28)$ & No stimulant medication $(n=69)$ & $p$ value \\
\hline Age & $6.1 \pm 0.3$ & $6.1 \pm 1.9$ & $6.0 \pm 1.7$ & 0.91 \\
\hline Sex, male/female & $78(80.4) / 19(19.6)$ & $24(85.7) / 4(14.3)$ & $54(78.3) / 15(21.7)$ & 0.40 \\
\hline Race/ethnicity, white/non-white & $62(63.9) / 35(36.1)$ & $21(75.0) / 7(25.0)$ & $41(59.4) / 28(40.6)$ & 0.79 \\
\hline Treatment duration & $161.9 \pm 106.2$ & $161.1 \pm 113.5$ & $163.8 \pm 87.3$ & 0.91 \\
\hline \multicolumn{5}{|l|}{ Clinical diagnoses } \\
\hline ADHD & $45(46.4)$ & $21(75.0)$ & $24(34.8)$ & \\
\hline ODD & $51(52.6)$ & $13(46.4)$ & $38(55.1)$ & \\
\hline $\mathrm{CD}$ & $2(2.0)$ & $1(3.6)$ & $1(1.4)$ & \\
\hline DBD not otherwise specified & $28(28.9)$ & $6(21.4)$ & $22(31.9)$ & \\
\hline DMDD & $3(3.1)$ & $0(0)$ & $3(4.3)$ & \\
\hline Reactive Attachment Disorder & $10(10.3)$ & $2(7.1)$ & $8(11.6)$ & \\
\hline Generalized Anxiety Disorder & $4(4.1)$ & $1(3.6)$ & $3(4.3)$ & \\
\hline Bipolar Disorder & $1(1.0)$ & $0(0)$ & $1(1.4)$ & \\
\hline Adjustment Disorder & $7(7.2)$ & $1(3.6)$ & $6(8.7)$ & \\
\hline PTSD & $8(8.2)$ & $4(14.3)$ & $4(5.8)$ & \\
\hline \multicolumn{5}{|l|}{ CBCL score profiles } \\
\hline Attentional problems & $65.9 \pm 9.2$ & $65.4 \pm 9.40$ & $67.0 \pm 8.9$ & 0.45 \\
\hline Aggressive behavior & $74.4 \pm 13.2$ & $74.6 \pm 13.9$ & $73.9 \pm 11.5$ & 0.82 \\
\hline Externalizing problems & $71.1 \pm 10.5$ & $71.2 \pm 11.1$ & $71.0 \pm 9.1$ & 0.94 \\
\hline ADHD-DSM & $65.5 \pm 9.0$ & $65.2 \pm 9.2$ & $66.3 \pm 8.5$ & 0.59 \\
\hline ODD-DSM & $70.6 \pm 8.4$ & $70.9 \pm 8.8$ & $69.9 \pm 7.5$ & 0.58 \\
\hline Irritability & $4.5 \pm 1.6$ & $4.6 \pm 1.5$ & $4.2 \pm 1.8$ & 0.24 \\
\hline CD-DSM & $73.9 \pm 9.4(n=51)$ & $71.2 \pm 9.2(n=19)$ & $75.6 \pm 9.3(n=32)$ & 0.11 \\
\hline
\end{tabular}

Values are presented as mean \pm standard deviation or number $(\%)$.

ADHD, Attention-Deficit/Hyperactivity Disorder; ODD, Oppositional Defiant Disorder; CD, Conduct Disorder; DBD, Disruptive Behavior Disorder; DMDD, Disruptive Mood Dysregulation Disorder; PTSD, Post-Traumatic Stress Disorder; DSM, Diagnostic and Statistical Manual of Mental Disorders.

this study, due to the characteristics of the behavioral intervention treatment provided, children with Autism Spectrum Disorder or Intellectual Disability were not enrolled in this program by the clinical assessment/decision. The chart review was completed by one researcher (Z.Z.) with previous experience of this process, to avoid inter-rater variability. Participants were included in analysis only if their use of psychiatric medications remained consistent (dose adjustment were permitted but not medication changes or additions). This excluded 6 participants from the original chart review (for the detailed description of the psychotropic medications prescribed for the participants; Supplementary Table 1, available online). We only included participants who had continuous program attendance for a minimum of 30 days, and had their parent-completed Child Behavior Checklist $(\mathrm{CBCL})$ at the beginning of enrollment and at the end of it. The average length of stay in the program for the participants was 161 days (standard deviation $=106.18$, range from 31 to 488 days). Based on the eligibility criteria, 97 patients were found to be available for this study in the time period of interest. The Institutional Review Board of our institution approved this retrospective chart review (for the screening and process of chart review, Supplementary Fig. 1; available online). The study was conducted under protocol number 586-16-EP of University of Nebraska Medical Center.

\section{Behavioral Intervention Program}

The participants were enrolled in a local, community-based treatment facility, where a daytime program of schooling and behavioral intervention was provided. The participants were in a classroom setting with teachers, as well as licensed therapists. Therapists were able to provide group, individual, and/or family therapy both inside and outside of the classroom as needed. The treatment program is based on the social interactional theory/bioecological system theory [36-38] focusing on appropriate social interaction of the child, providing positive reinforcement and consequences for the appropriate/inappropriate social interaction or behavior. The medication status of each participant including stimulant medication was determined/managed by his/her outpatient 
provider, child and adolescent psychiatrists or pediatricians. Although the providers kept close contact and collaboration with the behavioral intervention program, they were independent providers outside of the program.

\section{Child Behavior Checklist}

Pre-intervention and post-intervention $\mathrm{T}$ scores were obtained from the parent-completed CBCL [39]. This questionnaire has been found to be both reliable and effective in identifying various clinical disorders and quantifying the severity of several child and adolescent psychopathologies [40]. Particularly relevant to this study is that the scale has been shown to effectively track the severity of disruptive behavior and mood problems related to $\mathrm{CD}, \mathrm{ODD}$, and ADHD [41,42]. We also measured the level of irritability, which is highly prevalent among patients with DBD. Irritability was operationalized as summation of three items on the CBCL questionnaire ("temper tantrum or hot temper", "stubborn, sullen, or irritable", and "sudden changes in mood or feelings"), which have been shown to produce valid and reliable measurement of irritability in pediatric populations [43]. Post-intervention scores were collected at the date of completion of their continuous participation with the program, regardless of the reason for completing the program.

\section{Data Analyses}

The main outcomes of interest in this study were the various $\mathrm{CBCL}$ scores for disruptive behavior and mood problems obtained at the initiation and after completion of the behavioral modification program. This included the scores of Attention Problems, Aggressive Behavior, Externalizing Problems, ADHD-DSM, ODD-DSM, and the operationalized irritability score. For subset of participants $(n=51)$ who used the CBCL version for 6 years old and older, CD-DSM scores were also used for the analyses.

Stimulant prescription status was used as the major independent variable. This was assessed through collection of each patient's pre-treatment and post-treatment medication lists. Those who received at least one type of stimulant medication throughout the course of the treatment program were considered to have a positive stimulant status. Additionally, pre-intervention CBCL scores for each outcome were collected to be an additional covariate for analysis. Basic demographic information including age at presentation, sex, and ethnicity, as well as total treatment duration was collected as potential confounding factors. Independent sample $t$ tests and chi-squared tests were performed to compare group differences in baseline characteristics between those who have been prescribed stimulants and those who have not. Variables compared between the two groups included basic demographic characteristics such as age, sex, ethnicity, and treatment duration, as well as the pre-treatment scores for the outcomes of interest mentioned previously. Paired $t$ tests were also performed to assess for overall improvement in $\mathrm{CBCL}$ scores between the start and end of the behavioral modification program (pre- vs. post-treatment program enrollment).

ANCOVA analysis was then performed to compare post-treatment program enrollment $\mathrm{CBCL}$ scores between those participants taking stimulant medications and those not $(2 \times 2$ ANCOVA: Time (pre- vs. post-treatment program enrollment) by Stimulant medication status (on stimulant medication vs. no stimulant medication). Age, sex, ethnicity, and treatment duration, and baseline $\mathrm{CBCL}$ scores were controlled for as a covariate in the final model. Verification of all ANCOVA assumptions was performed using appropriate diagnostic tests. Analyses were completed through SPSS version 25 (IBM Co., Armonk, NY, USA).

\section{RESULTS}

A total of 97 participants were included for this retrospective review. Participants were predominantly male (78 of 97). Basic demographic characteristics of age, sex, and race, however, were not statistically different between the stimulant and no stimulant medication groups; see Table 1.

Between the two groups (the stimulant medication group vs. the no stimulant medication group), there were no significant differences in the baseline, pre-intervention CBCL scores of Attention Problems, Aggressive Behavior, Externalizing Problems, ADHD-DSM, ODD-DSM, CD-DSM, and irritability. Furthermore, mean duration of treatment program enrollment was not significantly different between the two groups; see Table 1.

Paired $t$ tests showed significant improvement in all of the $\mathrm{CBCL}$ scores (Attentional Problems, Aggressive Behavior, Externalizing Problems, ADHD-DSM, ODD-DSM, Irritability, and CD-DSM) after the completion of the pro- 
gram; see Table 2. This was valid for both groups (the stimulant medication group and the no stimulant medication group); see Table 3. The ANCOVA analysis revealed that there was no significant main effect of the stimulant medication status on the CBCL score changes of Attentional Problems, Aggressive Behavior, Externalizing Problems, ADHD-DSM, ODD-DSM, Irritability and CD-
DSM; see Table 4. Notably, there was a significant time by stimulant medication status interaction on CD-DSM score. The follow-up independent $t$ test on the score changes before and after the treatment program enrollment showed that the participants who received stimulant medication had significantly less decrease in the CD-DSM scores after the completion of the program enrollment,

Table 2. Pre- and post-intervention (treatment program enrollment) paired $t$ test results for main outcomes of interest

\begin{tabular}{lcccc}
\hline \multicolumn{1}{c}{ Variables } & Pre-intervention & Post-intervention & Paired $t$ value & $p$ value \\
\hline Attentional problems & $65.9 \pm 9.2$ & $61.9 \pm 8.4$ & 6.0 & $<0.001$ \\
Aggressive behavior & $74.4 \pm 13.2$ & $65.4 \pm 10.6$ & 9.4 & $<0.001$ \\
Externalizing problems & $71.1 \pm 10.5$ & $63.5 \pm 10.4$ & 9.3 & $<0.001$ \\
ADHD-DSM & $65.5 \pm 9.0$ & $61.2 \pm 8.2$ & 5.9 & $<0.001$ \\
ODD-DSM & $70.6 \pm 8.4$ & $62.9 \pm 9.1$ & 9.9 & $<0.001$ \\
Irritability & $4.5 \pm 1.6$ & $3.3 \pm 1.9$ & 7.3 & $<0.001$ \\
CD-DSM $(\mathrm{n}=51)$ & $73.9 \pm 9.4$ & $66.5 \pm 8.8$ & 6.9 & $<0.001$ \\
\hline
\end{tabular}

Values are presented as mean \pm standard deviation.

ADHD, Attention-Deficit/Hyperactivity Disorder; ODD, Oppositional Defiant Disorder; CD, Conduct Disorder; DSM, Diagnostic and Statistical Manual of Mental Disorders.

Table 3. Pre- and post-treatment program enrollment paired $t$ test results for main outcomes of interest, stratified by stimulant medication group

\begin{tabular}{|c|c|c|c|c|c|c|c|c|}
\hline \multirow[b]{2}{*}{ Variables } & \multicolumn{4}{|c|}{ On stimulants } & \multicolumn{4}{|c|}{ No stimulant medication } \\
\hline & $\begin{array}{l}\text { Pre- } \\
\text { intervention }\end{array}$ & $\begin{array}{l}\text { Post- } \\
\text { intervention }\end{array}$ & $\begin{array}{l}\text { Paired } \\
t \text { value }\end{array}$ & $p$ value & $\begin{array}{l}\text { Pre- } \\
\text { intervention }\end{array}$ & $\begin{array}{l}\text { Post- } \\
\text { intervention }\end{array}$ & $\begin{array}{l}\text { Paired } \\
t \text { value }\end{array}$ & $p$ value \\
\hline Attentional problems & $65.4 \pm 9.40$ & $63.2 \pm 9.1$ & 2.9 & 0.008 & $67.0 \pm 8.9$ & $61.3 \pm 8.1$ & 5.3 & $<0.001$ \\
\hline Aggressive behavior & $74.6 \pm 13.9$ & $65.9 \pm 10.2$ & 3.9 & 0.001 & $73.9 \pm 11.5$ & $65.2 \pm 10.8$ & 8.9 & $<0.001$ \\
\hline Externalizing problems & $71.2 \pm 11.1$ & $64.3 \pm 8.5$ & 4.6 & $<0.001$ & $71.0 \pm 9.1$ & $63.1 \pm 11.2$ & 9.8 & $<0.001$ \\
\hline ADHD-DSM & $65.2 \pm 9.2$ & $62.1 \pm 8.2$ & 2.8 & 0.010 & $66.3 \pm 8.5$ & $60.8 \pm 8.3$ & 5.2 & $<0.001$ \\
\hline ODD-DSM & $70.9 \pm 8.8$ & $62.6 \pm 8.7$ & 5.1 & $<0.001$ & $69.9 \pm 7.5$ & $63.1 \pm 9.3$ & 8.5 & $<0.001$ \\
\hline Irritability & $4.6 \pm 1.5$ & $3.1 \pm 1.8$ & 3.5 & 0.011 & $4.2 \pm 1.8$ & $3.4 \pm 1.9$ & 6.9 & $<0.001$ \\
\hline CD-DSM $(n=51)$ & $71.2 \pm 9.2$ & $65.9 \pm 9.9$ & 2.9 & 0.002 & $75.6 \pm 9.3$ & $65.5 \pm 8.3$ & 6.4 & $<0.001$ \\
\hline
\end{tabular}

Values are presented as mean \pm standard deviation.

ADHD, Attention-Deficit/Hyperactivity Disorder; ODD, Oppositional Defiant Disorder; CD, Conduct Disorder; DSM, Diagnostic and Statistical Manual of Mental Disorders.

Table 4. Time (pre- vs. post-program) by stimulant medication status (on stimulant vs. no stimulant medication) ANVOCA results

\begin{tabular}{|c|c|c|c|c|c|c|}
\hline \multirow[t]{2}{*}{ Variables } & \multicolumn{2}{|c|}{$\begin{array}{c}\text { Time by stimulant medication } \\
\text { status interaction }\end{array}$} & \multicolumn{2}{|c|}{$\begin{array}{l}\text { Main effect } \\
\text { of time }\end{array}$} & \multicolumn{2}{|c|}{$\begin{array}{c}\text { Main effect of stimulant } \\
\text { medication status }\end{array}$} \\
\hline & F value & $p$ value & F value & $p$ value & F value & $p$ value \\
\hline Attentional problems & 0.52 & 0.82 & 0.04 & 0.85 & 0.65 & 0.42 \\
\hline Aggressive behavior & 0.36 & 0.55 & 5.02 & 0.03 & 0.01 & 0.98 \\
\hline Externalizing problems & 0.74 & 0.39 & 6.74 & 0.01 & 0.02 & 0.88 \\
\hline ADHD-DSM & 0.01 & 0.98 & 2.32 & 0.13 & 0.24 & 0.62 \\
\hline ODD-DSM & 0.24 & 0.63 & 7.94 & 0.006 & 0.30 & 0.58 \\
\hline Irritability & 0.55 & 0.46 & 3.19 & 0.08 & 0.71 & 0.40 \\
\hline CD-DSM $(n=51)$ & 4.14 & $0.049 *$ & 0.03 & 0.87 & 0.44 & 0.51 \\
\hline
\end{tabular}

ADHD, Attention-Deficit/Hyperactivity Disorder; ODD, Oppositional Defiant Disorder; CD, Conduct Disorder; DSM, Diagnostic and Statistical Manual of Mental Disorders.

$* p<0.05$. 
compared to the participants who did not receive stimulant medications.

\section{DISCUSSION}

In this study, we investigated the effectiveness of stimulant medications on disruptive mood and behavior problems in young children (age 4-7) who were enrolled in an intensive outpatient treatment program. Participants showed significant improvement in CBCL scores for Attention Problems, Aggressive Behavior, Externalizing Problems, ADHD-DSM, ODD-DSM, CD-DSM, and irritability following completion of the treatment program. There was no main effect of stimulant medication status or significant time by stimulant medication status interaction on the $\mathrm{CBCL}$ score changes, however, and there was significantly less improvement in CD-DSM scores for children who received stimulant medications compared to those who did not.

This study further suggests that for young children, behavioral interventions that systematically provide positive reinforcement for appropriate, prosocial behavior and consequences for inappropriate, anti-social behavior can be effective modalities for treating disruptive mood and behavior problems. Because this information was obtained from a naturalistic, real-world environment, it provides particularly strong supportive evidence for this approach $[16,19,20]$. Therefore, our results indicate that behavioral intervention still needs to be considered the first-line treatment for young children [31]. However, it should be also noted that even after significant decrease, most of the symptom profiles remained in clinically significant range. In a very comprehensive follow-up study of preschoolers with ADHD, after 3-6 years of treatment most of the participants continued to show significant level of functional impairment even when continued on various medications including stimulants [44]. The 12 month follow-up of a treatment study of methylphenidate and risperidone for children with severe aggression also demonstrated continuation of a significant level of mental health issues after 12 months treatment with these medications combined with behavioral intervention [45]. These findings stress the persistent/chronic functional impairment these children struggle with, and importance of long-term, comprehensive intervention for this population. In addition it is critical to evaluate the actual clinical significance of treatment modality, not just efficacy or effectiveness [46], which warrants future study.

To our surprise, the hypothesis regarding additional effectiveness of stimulant medication for the disruptive behavior and mood problem profiles was not rejected. There was no significant improvement in the CBCL scores after the completion of the treatment program between those who received stimulant medications and those who did not. There are a few possible explanations for this result. First, there might be a ceiling effect with the behavioral intervention program, mainly due to the intensity and duration of the program the children were enrolled in. The daily, full-day outpatient setting for such a long duration is a relatively intensive setting for this population $[47,48]$. However, it is worth noting that although baseline problem profiles were not statistically different, the children who received stimulant medications showed a lower degree of improvement in their problems compared to the children who did not. Second, we did not measure the baseline problem profiles before the start of the stimulant medications, and there were no data available on for how long the patients were on the stimulant medications before their entry to the treatment program. It is possible that the participants who entered the program on stimulant medications were more impaired to begin with, and the medication allowed them to demonstrate a comparable response to peers not on stimulants at treatment program entry. However, it should be still stressed that for the relatively long course of treatment (average 162 days) the stimulant medications did not provide additional improvement in their core problem profiles, including the ones pertaining to the diagnosis of ADHD. A third possibility is that stimulant medications may not be as effective in younger children as they are for their older counterparts, potentially for both ADHD and disruptive behavior and mood problems, especially in a real-world setting. With limited data available on the long-term effects of stimulant medications on disruptive behavior and mood problems in young children, future research is needed.

To our knowledge, there has been only one study examining the effectiveness of stimulant medications for disruptive behavior in a real-world setting for children 5 years old and younger [49]. Although the study found that the stimulant medications were effective in reducing aggressive behavior, it did not use any specific problem/symptom profile scales to measure disruptive behav- 
ior disorders. Also, the number of participants in the study was small $(n=20)$, limiting its power. In contrast, our result would support previous research that suggests the potential of the brain immaturity that can have an impact on responses to medications in younger children [50], especially in the context of genetic and environmental factors [51].

The fact that CD-DSM scores actually showed less improvement in the subset of children receiving stimulant medications also requires careful examination. There is a previous study showing the efficacy of stimulant medication on CU trait of ADHD patients, for children of ages 7 to 12 [15]. In this study, although children with DBDs in both groups showed significant level of CD symptoms in baseline and follow-up, very few of them were diagnosed with $\mathrm{CD}$ ( 2 in total). This might be due to the fact that in clinical practice, $C D$ diagnosis usually occurs between middle childhood and middle adolescence [1], whereas our study groups were consisted of young children (ages between 4 and 7 years old). It is also possible that dimensional measurement of $\mathrm{CD}$ symptoms across various diagnoses of DBDs may provide more clinically relevant information in this population even without presence of the categorical diagnosis [29,30]. In addition, recent studies have shown that children exhibiting Conduct Disorder scores may represent a heterogeneous, complex population rather than single, homogeneous one $[52,53]$. The callous-unemotional traits have played a major part in providing dimensional characterization of Conduct Disorder symptom manifestations [54], and have therefore been incorporated into the new DSM- 5 as the "limited prosocial emotions specifier" [1]. Although the treatment facility did not measure callous-unemotional traits for their participants, this trait may have played a role in explaining why stimulant medications might be associated with our observed result of lower outcome CD scores compared with non-stimulant medication groups. Future study is warranted, especially to further assess the impact of callous-unemotional traits on the effectiveness and efficacy of stimulant medications for treatment of disruptive behavior and mood symptoms in young children.

There are several limitations of this study. First, we examined all stimulant medications as a combined entity (methylphenidate, dexmethylphenidate, lisdexamfetamine and amphetamine) instead of comparing them individually, due to the small sample size available for each medication. However, all these medications share common pharmacodynamics (mechanism of action), of enhancing the dopaminergic/norepinephrine systems [55]. Future study stratifying the classes, duration of action, and combination effect of the various stimulant medication is warranted. Second, we also included the participants who received multiple psychotropic medications in addition to the stimulant medications, which may have contributed to the poor response for disruptive behavior, due to side effects such as drowsiness and fatigue [56] (Supplementary Table 1). However, our subsequent analyses excluding these participants replicated the main findings, mitigating this concern (see the Supplemental Material and Supplementary Tables 2-4; available online). Third, we relied on the clinical characterization of the patients by the clinicians, not implementing a structured diagnostic interview. This might explain the large number of DBD NOS diagnosis (29\% or so), perhaps because it is very challenging to accurately diagnose DBDs especially in young children. However, the approach toward a dimensional symptom profile in a large number of participants should be able to counter-balance this limitation. Fourth, this was a retrospective, chart-review study, not a well-designed clinical trial. It can, however, be argued that this gives extra validity to the study in regard to the effectiveness of the treatment modalities in the naturalistic stetting [26]. Lastly, this is a single site study which may potentially have limitations of generalizing to the other intensive outpatient programs. The result should be complemented by future clinical trials especially for the efficacy/effectiveness of the stimulant medications in treating disruptive behavior and mood problems in this young population.

This study suggests a possibility that stimulant medications may not be effective at providing substantially greater outcomes for disruptive behavior and mood problems in young children (age 7 years old and younger) when combined with an intensive, outpatient-based behavioral modification program. Explanations for this may include a ceiling effect of the treatment program itself, a possible difference in true-baseline status between those participants who were on stimulant medications at entry and those who weren't, and even a potential differential response between young and older children to stimulant medications. Studies designed with these considerations in mind may identify which children and which symp- 
toms respond to which pharmacologic and non-pharmacologic interventions. In the meantime, careful clinical examination and assessment should be provided before initiation of treatment modalities for this age group to treat disruptive behavior and mood problems.

\section{Acknowledgments}

This work was supported by the National Institute of General Medical Sciences, National Institutes of Health (1U54GM115458-1), S.H. principal investigator. This study was also supported by the young investigator award by the Brain and Behavior Research Foundation.

\section{Conflicts of Interest}

No potential conflict of interest relevant to this article was reported.

\section{Author Contributions}

Conceptualization: Soonjo Hwang. Data acquisition: Ian Parsley, Zhuo Zhang, Mark Hausmann, Arica Lerdahl, and Brigette Vaughan. Formal analysis: Ian Parsley and Soonjo Hwang. Supervision: Ryan Edwards. Writingoriginal draft: Ian Parsley, Arica Lerdahl, Brigette Vaughan, and Soonjo Hwang. Writing - review \& editing: Zhuo Zhang, Mark Hausmann, and Ryan Edwards.

\section{ORCID}

Ian Parsley

Zhuo Zhang https://orcid.org/0000-0003-2431-6731

Mark Hausmann https://orcid.org/0000-0002-1367-4106

Arica Lerdahl https://orcid.org/0000-0002-6129-356X Brigette Vaughan https://orcid.org/0000-0002-6665-423X Ryan Edwards https://orcid.org/0000-0002-8578-9826 Soonjo Hwang https://orcid.org/0000-0001-9823-0872 https://orcid.org/0000-0001-5117-2468

\section{REFERENCES}

1. American Psychiatric Association. Diagnostic and statistical manual of mental disorders: DSM-5. Washington, DC:American Psychiatric Association;2013.

2. Hwang S, Meffert H, VanTieghem MR, Sinclair S, Bookheimer SY, Vaughan B, et al. Dysfunctional social reinforcement processing in disruptive behavior disorders: an functional magnetic resonance imaging study. Clin Psychopharmacol Neurosci 2018;16:449-460.

3. Connor DF, Steeber J, McBurnett K. A review of attention-deficit/hyperactivity disorder complicated by symptoms of oppositional defiant disorder or conduct disorder. J Dev Behav
Pediatr 2010;31:427-440.

4. Becker SP, Luebbe AM, Langberg JM. Co-occurring mental health problems and peer functioning among youth with attention-deficit/hyperactivity disorder: a review and recommendations for future research. Clin Child Fam Psychol Rev 2012;15:279-302.

5. Willcutt EG, Pennington BF, Chhabildas NA, Friedman MC, Alexander J. Psychiatric comorbidity associated with DSM-IV $A D H D$ in a nonreferred sample of twins. J Am Acad Child Adolesc Psychiatry 1999;38:1355-1362.

6. Biederman J, Petty CR, Day H, Goldin RL, Spencer T, Faraone $\mathrm{SV}$, et al. Severity of the aggression/anxiety-depression/attention child behavior checklist profile discriminates between different levels of deficits in emotional regulation in youth with attention-deficit hyperactivity disorder. J Dev Behav Pediatr 2012;33:236-243.

7. Masi G, Muratori P, Manfredi A, Pisano S, Milone A. Child behaviour checklist emotional dysregulation profiles in youth with disruptive behaviour disorders: clinical correlates and treatment implications. Psychiatry Res 2015;225:191-196.

8. Zenglein Y, Schwenck C, Westerwald E, Schmidt C, Beuth S, Meyer J, et al. Empirically determined, psychopathological subtypes in children with ADHD. J Atten Disord 2016;20:96107.

9. Van der Oord S, Prins PJ, Oosterlaan J, Emmelkamp PM. Efficacy of methylphenidate, psychosocial treatments and their combination in school-aged children with ADHD: a meta-analysis. Clin Psychol Rev 2008;28:783-800.

10. Nock MK, Kazdin AE, Hiripi E, Kessler RC. Prevalence, subtypes, and correlates of DSM-IV conduct disorder in the National Comorbidity Survey Replication. Psychol Med 2006;36:699-710.

11. Leibenluft E, Stoddard J. The developmental psychopathology of irritability. Dev Psychopathol 2013;25(4 Pt 2):1473-1487.

12. Avenevoli S, Blader JC, Leibenluft E. Irritability in youth: an update. J Am Acad Child Adolesc Psychiatry 2015;54:881883.

13. Kutcher S, Aman M, Brooks SJ, Buitelaar J, van Daalen E, Fegert J, et al. International consensus statement on attention-deficit/hyperactivity disorder (ADHD) and disruptive behaviour disorders (DBDs): clinical implications and treatment practice suggestions. Eur Neuropsychopharmacol 2004;14: 11-28.

14. Ollendick TH, Greene RW, Austin KE, Fraire MG, Halldorsdottir T, Allen KB, et al. Parent management training and collaborative \& proactive solutions: a randomized control trial for oppositional youth. J Clin Child Adolesc Psychol 2016;45:591-604.

15. Waschbusch DA, Carrey NJ, Willoughby MT, King S, Andrade BF. Effects of methylphenidate and behavior modification on the social and academic behavior of children with disruptive behavior disorders: the moderating role of callous/unemotional traits. J Clin Child Adolesc Psychol 2007;36:629-644. 
16. Steiner $\mathrm{H}$, Remsing L. Practice parameter for the assessment and treatment of children and adolescents with oppositional defiant disorder. J Am Acad Child Adolesc Psychiatry 2007; 46:126-141.

17. Juárez-Treviño M, Esquivel AC, Isida LML, Delgado DÁG, de la O Cavazos ME, Ocañas LG, et al. Clozapine in the treatment of aggression in conduct disorder in children and adolescents: a randomized, double-blind, controlled trial. Clin Psychopharmacol Neurosci 2019;17:43-53.

18. Pliszka S. Practice parameter for the assessment and treatment of children and adolescents with attention-deficit/hyperactivity disorder. J Am Acad Child Adolesc Psychiatry 2007; 46:894-921.

19. Brestan EV, Eyberg SM. Effective psychosocial treatments of conduct-disordered children and adolescents: 29 years, 82 studies, and 5,272 kids. J Clin Child Psychol 1998;27:180189.

20. Kazdin AE. Parent management training: treatment for oppositional, aggressive, and antisocial behavior in children and adolescents. New York:Oxford University Press;2005.

21. Langberg JM, Becker SP. Does long-term medication use improve the academic outcomes of youth with attention-deficit/hyperactivity disorder? Clin Child Fam Psychol Rev 2012; 15:215-233.

22. Pringsheim T, Hirsch L, Gardner D, Gorman DA. The pharmacological management of oppositional behaviour, conduct problems, and aggression in children and adolescents with attention-deficit hyperactivity disorder, oppositional defiant disorder, and conduct disorder: a systematic review and meta-analysis. Part 1: psychostimulants, alpha-2 agonists, and atomoxetine. Can J Psychiatry 2015;60:42-51.

23. Connor DF, Glatt SJ, Lopez ID, Jackson D, Melloni RH Jr. Psychopharmacology and aggression. I: a meta-analysis of stimulant effects on overt/covert aggression-related behaviors in ADHD. J Am Acad Child Adolesc Psychiatry 2002;41:253261.

24. Klein RG, Abikoff H, Klass E, Ganeles D, Seese LM, Pollack S. Clinical efficacy of methylphenidate in conduct disorder with and without attention deficit hyperactivity disorder. Arch Gen Psychiatry 1997;54:1073-1080.

25. Kutlu A, Akyol Ardic U, Ercan ES. Effect of methylphenidate on emotional dysregulation in children with attention-deficit/hyperactivity disorder + oppositional defiant disorder/ conduct disorder. J Clin Psychopharmacol 2017;37:220-225.

26. Gartlehner G, Hansen RA, Nissman D, Lohr KN, Carey TS. Criteria for distinguishing effectiveness from efficacy trials in systematic reviews. Rockville (MD):Agency for Healthcare Research and Quality (US);2006.

27. Pelham WE, Smith BH, Evans SW, Bukstein O, Gnagy EM, Greiner AR, et al. The effectiveness of short- and long-acting stimulant medications for adolescents with $A D H D$ in a naturalistic secondary school setting. J Atten Disord 2017;21:40-45.

28. Smith BH, Pelham WE, Evans S, Gnagy E, Molina B, Bukstein
$\mathrm{O}$, et al. Dosage effects of methylphenidate on the social behavior of adolescents diagnosed with attention-deficit hyperactivity disorder. Exp Clin Psychopharmacol 1998;6:187-204.

29. Insel T, Cuthbert B, Garvey M, Heinssen R, Pine DS, Quinn K, et al. Research domain criteria (RDoC): toward a new classification framework for research on mental disorders. Am J Psychiatry 2010;167:748-751.

30. Cuthbert BN, Insel TR. Toward the future of psychiatric diagnosis: the seven pillars of RDoC. BMC Med 2013;11:126.

31. Subcommittee on Attention-Deficit/Hyperactivity Disorder; Steering Committee on Quality Improvement and Management, Wolraich M, Brown L, Brown RT, DuPaul G, et al. ADHD: clinical practice guideline for the diagnosis, evaluation, and treatment of attention-deficit/hyperactivity disorder in children and adolescents. Pediatrics 2011;128:1007-1022.

32. Greenhill L, Kollins S, Abikoff H, McCracken J, Riddle M, Swanson J, et al. Efficacy and safety of immediate-release methylphenidate treatment for preschoolers with $A D H D$. J Am Acad Child Adolesc Psychiatry 2006;45:1284-1293.

33. Vitiello B. Psychopharmacology for young children: clinical needs and research opportunities. Pediatrics 2001;108:983-989.

34. Zito JM, Safer DJ, dosReis S, Gardner JF, Boles M, Lynch F. Trends in the prescribing of psychotropic medications to preschoolers. JAMA 2000;283:1025-1030.

35. Gleason MM, Egger HL, Emslie GJ, Greenhill LL, Kowatch RA, Lieberman AF, et al. Psychopharmacological treatment for very young children: contexts and guidelines. I Am Acad Child Adolesc Psychiatry 2007;46:1532-1572.

36. Bronfenbrenner U. Making human beings human: bioecological perspectives on human development. Thousand Oaks:Sage Publications;2005.

37. Bronfenbrenner U, Ceci SJ. Nature-nurture reconceptualized in developmental perspective: a bioecological model. Psychol Rev 1994; 101:568-586.

38. Patterson GR, Reid JB, Dishion TJ. Antisocial boys: a social interactional approach. Eugene, OR:Castalia Publishing Company; 1992.

39. Achenbach TM. Achenbach system of empirically based assessment (ASEBA): development, findings, theory, and applications. Burlington, Vt:University of Vermont, Research Center of Children, Youth \& Families;2009.

40. Achenbach TM, Dumenci L, Rescorla LA. DSM-oriented and empirically based approaches to constructing scales from the same item pools. J Clin Child Adolesc Psychol 2003;32:328-340.

41. Hudziak JJ, Copeland W, Stanger C, Wadsworth M. Screening for DSM-IV externalizing disorders with the Child Behavior Checklist: a receiver-operating characteristic analysis. J Child Psychol Psychiatry 2004;45:1299-1307.

42. Lowe LA. Using the Child Behavior Checklist in assessing conduct disorder: issues of reliability and validity. Res SoC Work Pract 1998;8:286-301.

43. Tseng WL, Moroney E, Machlin L, Roberson-Nay R, Hettema $\mathrm{JM}$, Carney D, et al. Test-retest reliability and validity of a frus- 
tration paradigm and irritability measures. I Affect Disord 2017;212:38-45.

44. Vitiello B, Lazzaretto D, Yershova K, Abikoff H, Paykina N, McCracken JT, et al. Pharmacotherapy of the Preschool ADHD Treatment Study (PATS) children growing up. J Am Acad Child Adolesc Psychiatry 2015;54:550-556.

45. Gadow KD, Brown NV, Arnold LE, Buchan-Page KA, Bukstein OG, Butter E, et al. Severely aggressive children receiving stimulant medication versus stimulant and risperidone: 12-month follow-up of the TOSCA trial. I Am Acad Child Adolesc Psychiatry 2016;55:469-478.

46. Jacobson NS, Truax P. Clinical significance: a statistical approach to defining meaningful change in psychotherapy research. J Consult Clin Psychol 1991;59:12-19.

47. Cook MN, Crisostomo PS, Simpson TS, Williams JD, Wamboldt MZ. Effectiveness of an intensive outpatient program for disruptive children: initial findings. Community Ment Health J 2014;50:164-171.

48. Burns BJ, Hoagwood K, Mrazek PJ. Effective treatment for mental disorders in children and adolescents. Clin Child Fam Psychol Rev 1999;2:199-254.

49. Staller JA. Psychopharmacologic treatment of aggressive preschoolers: a chart review. Prog Neuropsychopharmacol Biol Psychiatry 2007;31:131-135.
50. Loureiro-Vieira S, Costa VM, de Lourdes Bastos M, Carvalho F, Capela JP. Methylphenidate effects in the young brain: friend or foe? Int J Dev Neurosci 2017;60:34-47.

51. Lenroot RK, Schmitt JE, Ordaz SJ, Wallace GL, Neale MC, Lerch JP, et al. Differences in genetic and environmental influences on the human cerebral cortex associated with development during childhood and adolescence. Hum Brain Mapp 2009;30:163-174.

52. Blair RJ, White SF, Meffert H, Hwang S. Disruptive behavior disorders: taking an RDoC(ish) approach. Curr Top Behav Neurosci 2014;16:319-336.

53. Hwang S, Nolan ZT, White SF, Williams WC, Sinclair S, Blair RJ. Dual neurocircuitry dysfunctions in disruptive behavior disorders: emotional responding and response inhibition. Psychol Med 2016;46:1485-1496.

54. Frick PJ. Developmental pathways to conduct disorder: implications for future directions in research, assessment, and treatment. J Clin Child Adolesc Psychol 2012;41:378-389.

55. Wilens TE. Mechanism of action of agents used in attention-deficit/hyperactivity disorder. J Clin Psychiatry 2006;67 Suppl 8:32-38.

56. Loy JH, Merry SN, Hetrick SE, Stasiak K. Atypical antipsychotics for disruptive behaviour disorders in children and youths. Cochrane Database Syst Rev 2017;8:CD008559. 